University of Nebraska - Lincoln

DigitalCommons@University of Nebraska - Lincoln

Management Department Faculty Publications

Management Department

2009

\title{
Operations Research Methodology Life Cycle Trend Phases as Recorded in Journal Articles
}

Marc J. Schniederjans

University of Nebraska - Lincoln, mschniederjans1@unl.edu

A. M. Schniederjans

Johns Hopkins University, Baltimore, MD, USA

D. G. Schniederjans

Texas Tech University, Lubbock, TX, USA

Follow this and additional works at: https://digitalcommons.unl.edu/managementfacpub

Part of the Management Sciences and Quantitative Methods Commons

Schniederjans, Marc J.; Schniederjans, A. M.; and Schniederjans, D. G., "Operations Research Methodology Life Cycle Trend Phases as Recorded in Journal Articles" (2009). Management Department Faculty Publications. 33.

https://digitalcommons.unl.edu/managementfacpub/33

This Article is brought to you for free and open access by the Management Department at DigitalCommons@University of Nebraska - Lincoln. It has been accepted for inclusion in Management Department Faculty Publications by an authorized administrator of DigitalCommons@University of Nebraska - Lincoln. 
Published in Journal of the Operational Research Society 60 (2009), pp. 881-894; doi 10.1057/palgrave.jors.2602629 Copyright (C) 2009 Operational Research Society Ltd.; published by Palgrave-Macmillan. Used by permission. http://www.palgrave-journals.com/jors/

\title{
Operations research methodology life cycle trend phases as recorded in journal articles
}

\author{
M. J. Schniederjans, ${ }^{1}$ A. M. Schniederjans, ${ }^{2}$ and D. G. Schniederjans ${ }^{3}$ \\ 1 University of Nebraska-Lincoln, Lincoln, NE, USA \\ 2 Johns Hopkins University, Baltimore, MD, USA \\ 3 Texas Tech University, Lubbock, TX, USA \\ Corresponding author - M. J. Schniederjans, College of Business Administration, University of Nebraska-Lincoln, \\ Lincoln, NE 68588-0491, USA, email mschniederjans1@unl.edu
}

\begin{abstract}
This paper applies life cycle concepts to forecast and explore trends in the publication rates of operations research (OR) methodology journal articles. The confirmatory part of this study seeks to show the accuracy of life cycles to forecast a trend for a single OR methodology. The exploratory part of this study extends the use of life cycle forecasting to a broader collection of OR methodologies. This part of the study entails a collection of keywords for OR methodologies from over 8,000 journal articles. The results show a life cycle can be used to forecast a trend in OR journal article methodology productivity based on keyword listings. This paper also reveals trends in methodology usage for leading OR journals in Europe and the US. The existence and use of life cycle trends in the OR methodology research have ramifications on new directions for research, research funding, and OR textbook content.
\end{abstract}

Keywords: FC forecasting, MO multi-objective, LP, RG regression analysis

\section{Introduction}

Operations research (OR) theorists and practitioners have to stay current with the practice and use of methodologies in their field. One way to keep up with OR methodology utilization is to observe trends in their usage as reported in the OR literature, and to see where those trends are leading. A life cycle is a conceptual tool that can be used in identifying trends. A life cycle can be defined as a series of time-related phases or trend segments of activity that something (e.g., product) passes through during its lifetime. A particular time-related position on a life cycle is usually identified as falling into one of four distinct phases that make up the traditional product life cycle presented in Figure 1 (Grieves, 2005; Saaksyuori and Immonen, 2005). The horizontal time axis of a life cycle is divided into four phases or segments that make up the entire life cycle function. Those phases are characterized as introduction (slow rate of growth), growth (growth at an increasing rate), maturity (downward concave growth), and decline (negative growth). The vertical axis represents some frequency or measurement of activity that defines the level of life. Other life cycles will possess the four phases or trend segments, but may repeat the four phases over an extended period of time (Grieves, 2005).

Life cycle research has been the basis of forecasting a wide variety of behavior. Recognizing where an organization or a product is positioned on its life cycle is viewed by
Hellman (1994) and others as a critical first step in planning for the future. These and other life cycle studies (e.g. Du and Kamakura, 2006) have consistently shown that identifying the phase of a life cycle is a critical precursor to using the life cycle for forecasting purposes.

Phases of life cycles can be applied to studying research productivity trends (i.e., research article contributions to the literature). Lehman (1953) first proposed a scientist's age impacts research productivity. Later research by Allison and Steward (1974), Bayer and Dutton (1977), Cole (1979), Allison et al. (1982), and Diamond (1986) provides empirical evidence of the life cycle age of scientists' connection to research productivity. Levin and Stephan (1991) sought to overcome limitations in the prior research by providing a comprehensive, longitudinal study to examine the effects of aging on different groups of scientists. They found life cycle phases of research productivity are present as scientists age, following the typical stages of a life cycle as presented in Figure 1.

Since prior life cycle research suggests an individual scientist's research productivity follows a life cycle, it may be that OR methodologies might have their own unique life cycles. One study by Schniederjans (1995) established a life cycle for the OR methodology of goal programming (GP). Schniederjans found a sample of GP articles, when plotted over GP's then 35-year history, significantly followed the same general lazy-S function of the traditional product life cycle depicted in Figure 1. That study pre- 


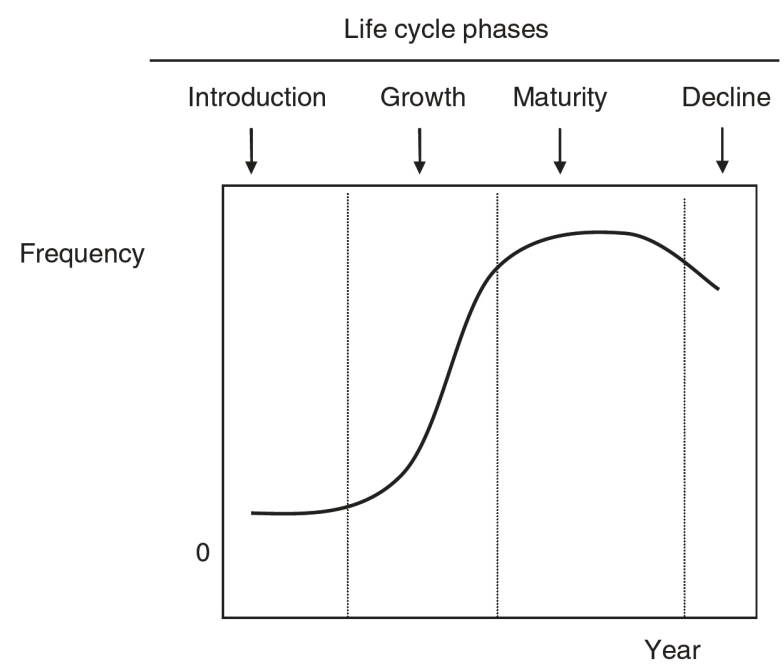

Figure 1. Traditional life cycle and phases.

dicted the frequency of GP journal articles had entered a decline phase in its life cycle and concluded the number of GP articles published in the future would follow a downward trend.

In this paper we first seek to test a proposition to determine if the decline phase for GP articles originally forecast in Schniederjans (1995) is accurate when compared to actual publications, since the time of that study. The term, "publications," as used in this paper refers exclusively to articles published in journals and does not include books, papers published in books, research reports/working papers or proceedings. Levin and Stephan (1991) also limited their life cycle research to journal articles, which are generally recognized as a primary measure of research productivity for scientists.

In a second exploratory section of this paper, we seek to determine if life cycle phases exist for a collection of common OR methodologies presented in the literature. This would represent a unique contribution to life cycle research, since no one to date has shown the existence of life cycles for a collection of methodologies representing a field of study.

The remainder of this paper is organized as follows. The next section presents the analysis of the results for the proposition of GP life cycle forecasting accuracy. The subsequent section presents the analysis of the results for the collection of OR methodology life cycle phases. The penultimate section discusses some of the implications of the life cycle results. The final section makes some concluding remarks.

\section{Confirming the forecast accuracy of the original GP life cycle model}

The term, GP, first appears in Charnes and Cooper's (1961) LP textbook, Management Models and Industrial Applications of Linear Programming. In Schniederjans (1995), only GP journal articles from 1961 to 1993 were included in the life cycle analysis. Based on these years, Schniederjans
Table 1. Forecast values for GP articles using original 1995 regression model

\begin{tabular}{lccrr} 
& $\begin{array}{c}\text { Regression } \\
\text { model } \\
\text { input } \\
\text { Actual }\end{array}$ & $\begin{array}{c}\text { Forecast } \\
\text { of journal } \\
\text { article } \\
\text { frequency* }\end{array}$ & $\begin{array}{c}\text { Actual } \\
\text { journal } \\
\text { article } \\
\text { frequency }\end{array}$ & \multicolumn{1}{c}{ Error } \\
1994 & 12 & 38.202 & 34 & 4.202 \\
1995 & 13 & 35.741 & 35 & 0.741 \\
1996 & 14 & 33.28 & 29 & 4.280 \\
1997 & 15 & 30.819 & 25 & 5.819 \\
1998 & 16 & 28.358 & 29 & -0.642 \\
1999 & 17 & 25.897 & 24 & 1.897 \\
2000 & 18 & 23.436 & 21 & 2.436 \\
2001 & 19 & 20.975 & 23 & -2.025 \\
2002 & 20 & 18.514 & 22 & -3.496 \\
2003 & 21 & 16.053 & 14 & 2.053 \\
2004 & 22 & 13.592 & 12 & 1.592 \\
* Original regression model from Schniederjans (1995): $\Upsilon=67.734$ \\
- 2.461X.
\end{tabular}

identified a non-linear life cycle for the GP publications reported in the literature that mimics the traditional product life cycle in Figure 1 ending with a declining trend. He went on to develop a linear model to approximate the decline period trend phase using just the decline trend years 1983-1992:

$$
Y_{\mathrm{p}}=67.734-2.461 X
$$

where $Y_{p}$ is the dependent variable or predicted forecast value for the number of GP articles per year, and $X$ is the year or independent variable numbered $1,2, \ldots, 10$. Based on using the model in Expression (1), Schniederjans (1995) demonstrated an accurate means of forecasting future GP article publications. It is significant to note that the decline trend phase equation above is based only upon the decline years or decline trend segment of the life cycle. This suggests that a sampling of a life cycle (one that captures a life cycle phase) may be adequate to forecast a future trend.

More than a decade has passed since that limited test of accuracy was conducted. We are now able to provide a more comprehensive and confirmatory test of the accuracy of the life cycle based on a larger ex post sampling. Specifically, we seek to determine if the life cycle trend forecast in Expression (1) remains an accurate measure of the future trend of the GP articles.

Proposition 1: The linear trend model of life cycle decline trend phase for GP article publications from Schniederjans (1995) accurately predicts the future trend observed in the number of GP journal articles.

To test this proposition, GP articles for 1994-2004 were collected using the same databases and methods utilized in the original study (see Schniederjans (1995) for sampling characteristics). The frequencies of the observed 268 GP journal articles collected from over 30 different journals by year are presented in Table 1. Utilizing the input year numbering system in Expression (1) for the 11 years, forecasts of GP 


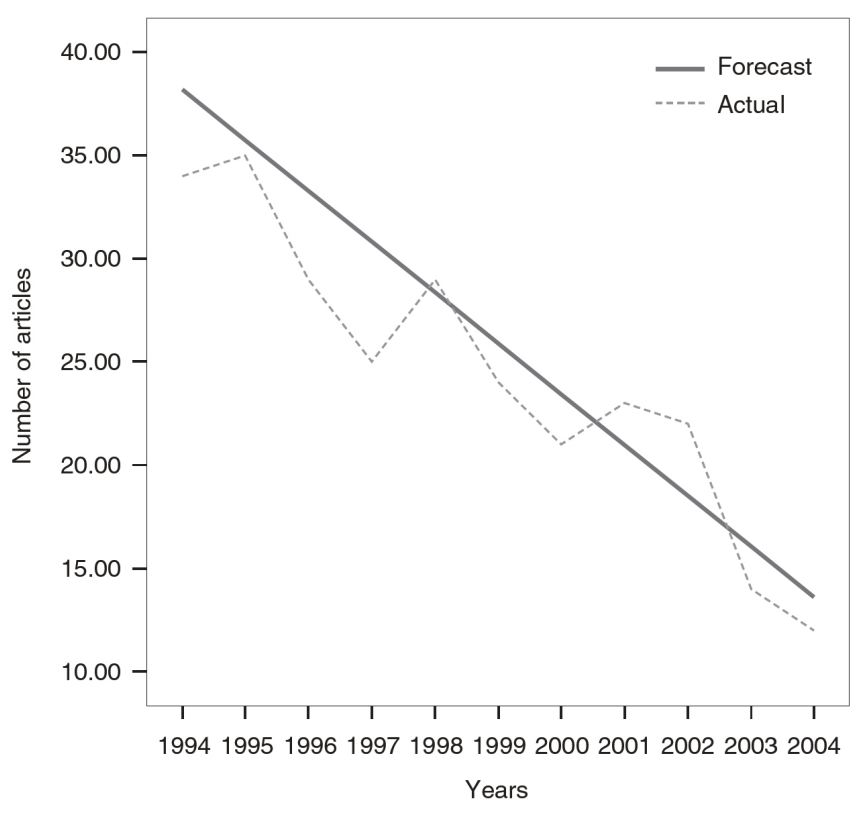

Figure 2. GP regression model forecast and actual article frequencies.

journal articles were computed. These forecasts and their resulting error values are presented in Table 1. Plotting the forecast and the actual values from Table 1 in Figure 2, the linear forecast model depicts a good fit to the actual number of journal publications each year. The overall declining trend in the actual number of GP articles during 1994-2004 is represented in the linear forecast model in Figure 2.

To formally measure the trend phase predictability of the model as suggested by Spurr and Bonini (1973), an additional regression model and its resulting coefficient of determination, $r^{2}$, and F-test are used (pp. 586-603). We are assuming, as did Schniederjans (1995), that a statistically significant correlation and regression model between actual and forecasted values constitutes a means of identifying trends. Utilizing SPSS 13.0 for Windows, the actual and forecasted values from Table 1 were regressed in a linear model. The results presented in Table 2 show the actual and forecasted values are highly related $\left(r^{2}=0.886, P\right.$ $<0.01)$. The resulting significant F-test $(P<0.001)$ of the regression model further supports the significance of the actual and forecasted trend values being related. As such, we conclude Proposition 1 is true, and the actual trend of a life cycle phase for the use of GP methodology in journal article research can be accurately approximated by a model based on historic journal article data. The results also confirm the predictability of phases in life cycles originally suggested in Schniederjans (1995).

\section{Exploratory research on the life cycle phases of OR methodologies}

If, as the proposition above suggests, that life cycle phases for GP publications can be used to estimate future trends in
Table 2. Statistics for regression of GP forecast and actual article frequencies

\begin{tabular}{lccccc}
\hline Model & $r^{2 *}$ & $F$ & df1 & df2 & Sig. \\
\hline Linear & 0.886 & 70.150 & 1 & 9 & 0.000 \\
\hline
\end{tabular}

* Significant at the 0.01 level (two-tailed).

journal article publications accurately, then it may be possible that other OR methodologies also have life cycle phases. These life cycle phase trends might be useful in predicting future trends in publications for these methodologies with a sampling of life cycle data.

One way of proving the existence of a life cycle is to show its similarity to phases in a traditional life cycle. Diamond (1984) and Levin and Stephan (1991) used a similar approach to demonstrate the existence of life cycles. For this study we gathered data on a variety of OR methodologies. Owing to the large number of articles published during the years 1994-2004 related to OR methodologies, the sampling process was limited to articles in just four journals: European Journal of Operational Research, Journal of the Operational Research Society, Management Science, and Operations Research. It is assumed in this paper that these four journals from Europe and the US provide a representative sampling of OR journals articles written in English. These journals are also considered to be sources of leading-edge research in their respective geographic locations offering a collection of the latest and innovative developments in the OR field (see http://www.isworld.org/csaunders/lsu.htm and also http://www.bwa.unisg.ch/org/bwa/web.nsf/SysWebRessources/JRL-Habilliste+Februar+2007/\$FILE/JRLHabilliste+Februar+2007.pdf). While acknowledging that many other journals publish OR articles, we assume the recognized quality of the aforementioned journals provide an adequate percentage of the higher quality articles for our sampling purposes. A total of 8609 articles were published in the four journals during the 1994-2004 period. These articles are used as the basis for this research.

To ensure objectivity in the citation counts, keywords were used to identify the types of OR methodologies used in the journal articles. We believe keywords are the best descriptors of the content of an article, since they undergo reviews by authors, editors, and academic reviewers. We also included journal articles' keyword citations with either application or algorithm content, since both represent a usage of OR methodology. Table 3 provides a summary of the totals for articles and keywords used in this study.

We next developed a framework in which the keywords could be grouped. A framework is critical in identifying methodologies, because some OR methodologies can fall into a variety of differing methodological categories. To identify the framework, we initially began reviewing the most common OR methodologies listed as chapter headings in a review of the OR textbooks published in Eng- 
Table 3. Journal article and keyword data for years 1994-2004 in OR, MS, JORS, and EJOR

\begin{tabular}{lcccc}
\hline Journal & $\begin{array}{c}\text { Range of yearly } \\
\text { journal articles } \\
\text { 1994-2004 }\end{array}$ & $\begin{array}{c}\text { Total } \\
\text { journal articles } \\
1994-2004\end{array}$ & $\begin{array}{c}\text { Range in number of } \\
\text { keywords per issue } \\
\text { during 1994-2004 }\end{array}$ & $\begin{array}{c}\text { Total keywords for } \\
\text { all articles during } \\
1994-2004\end{array}$ \\
\hline Operations Research (OR) & $71-102$ & 923 & $153-207$ & 1,987 \\
Management Science (MS) & $114-145$ & 1,373 & $442-634$ & 6,073 \\
Journal of the Operational & $111-185$ & 1,450 & $368-598$ & 5,452 \\
$\quad \begin{array}{l}\text { Research Society (JORS) } \\
\text { European Journal of } \\
\quad \text { Operational Research (EJOR) }\end{array}$ & $403-519$ & 4,863 & $1,338-1,708$ & 16,228 \\
Total & & & \\
\hline
\end{tabular}

Table 4. Listing of major methodology categories and frequencies

\begin{tabular}{|c|c|c|c|c|}
\hline No. & $\begin{array}{l}\text { Major methodology } \\
\text { citation categories }\end{array}$ & Content & $\begin{array}{r}\text { Total frequency of } \\
\text { citation } 1\end{array}$ & keyword \\
\hline 1 & Linear programming & All algorithms and applications & & 284 \\
\hline 2 & Sensitivity analysis and duality & All algorithms and applications & Parametric programming & 220 \\
\hline 3 & Network analysis & All algorithms and applications & $\begin{array}{l}\text { Shortest-route, minimal } \\
\text { spanning tree, PERT-CPM, } \\
\text { flow models }\end{array}$ & 677 \\
\hline 4 & Dynamic programming & All algorithms and applications & $\begin{array}{l}\text { Deterministic models, } \\
\text { probabilistic models }\end{array}$ & 331 \\
\hline 5 & Game theory & All algorithms and applications & & 232 \\
\hline 6 & Integer programming & All algorithms and applications & $\begin{array}{l}\text { Branch-and-bound, Programming; } \\
\text { Gomory, mixed integer, zero-one }\end{array}$ & 856 \\
\hline 7 & Non-linear programming & All algorithms and applications & $\begin{array}{l}\text { Single/multiple variable optimization, } \\
\text { Kuhn-Tucker, Lagrange, Programming; } \\
\text { quadratic, separable, convex, geometric, } \\
\text { polynomial, gradient search, fractional }\end{array}$ & 759 \\
\hline 8 & Markov analysis & All algorithms and applications & & 240 \\
\hline 9 & Queuing analysis & All algorithms and applications & & 480 \\
\hline 10 & Inventory analysis & All algorithms and applications & $\begin{array}{l}\text { Deterministic models, stochastic models, } \\
\text { control models }\end{array}$ & 557 \\
\hline 11 & Decision analysis & All algorithms and applications & Decision trees, utility analysis & 484 \\
\hline 12 & Simulation analysis & All models and applications & & 520 \\
\hline 13 & Heuristics analysis & All algorithms and applications & $\begin{array}{l}\text { Simulated annealing, meta-heuristics, } \\
\text { search methods }\end{array}$ & 1134 \\
\hline 14 & Multi-criteria decision making & All algorithms and applications & $\begin{array}{l}\text { Goal programming, multiobjective } \\
\text { programming, scoring/rating methods }\end{array}$ & 739 \\
\hline 15 & Analytic hierarchy process & All algorithms and applications & & 118 \\
\hline 16 & Forecasting analysis & All algorithms and applications & Time series analysis & 159 \\
\hline 17 & Statistical analysis & All algorithms and applications & $\begin{array}{l}\text { Regression, probability, reliability, } \\
\text { Bayesian analysis, confidence } \\
\text { analysis, combinatorics, risk analysis }\end{array}$ & 1021 \\
\hline 18 & $\begin{array}{l}\text { Assignment method and } \\
\text { Transportation method }\end{array}$ & All algorithms and applications & & 232 \\
\hline
\end{tabular}


Table 5 Resulting predictive model equations, statistics, and life cycle phases for major methodology categories

\begin{tabular}{|c|c|c|c|c|c|c|c|c|c|c|c|c|}
\hline No & $\begin{array}{l}\text { Major methodology } \\
\text { o. citation categories }\end{array}$ & Equation & $R^{2}$ & $F$ & df1 & df2 & Sig. & Constant & $b 1$ & $b 2$ & $b 3$ & $\begin{array}{l}\text { Life cycle } \\
\text { phase }\end{array}$ \\
\hline 1 & Linear programming & Linear & $0.457^{*}$ & 7.582 & 1 & 9 & 0.022 & 33.836 & -1.336 & & & Decline \\
\hline 2 & $\begin{array}{l}\text { Sensitivity analysis } \\
\text { and duality }\end{array}$ & Compound $†$ & $0.598^{*}$ & 13.413 & 1 & 9 & 0.005 & 26.170 & 0.954 & & & Decline \\
\hline 3 & Network analysis & Linear & $0.800^{*}$ & 36.052 & 1 & 9 & 0.000 & 79.655 & -3.064 & & & Decline \\
\hline 6 & Integer programming & Compound $\dagger$ & $0.397^{*}$ & 5.931 & 1 & 9 & 0.038 & 97.132 & 0.956 & & & Decline \\
\hline 7 & Non-linear programming & Compound $†$ & $0.943^{*}$ & 148.383 & 1 & 9 & 0.000 & 81.164 & 0.965 & & & Decline \\
\hline 8 & Markov analysis & Inverse & $0.581^{*}$ & 12.496 & 1 & 9 & 0.006 & 15.866 & 16.382 & & & Decline \\
\hline 9 & Queuing analysis & Logarithmic & $0.713^{*}$ & 22.396 & 1 & 9 & 0.001 & 60.997 & -11.483 & & & Decline \\
\hline 10 & Inventory analysis & Linear & 0.025 & 0.234 & 1 & 9 & 0.640 & 53.364 & -0.455 & & & No sig. pattern \\
\hline 14 & $\begin{array}{l}\text { Multi-criteria } \\
\text { decision making }\end{array}$ & Linear & 0.281 & 3.519 & 1 & 9 & 0.093 & 56.164 & 1.836 & & & No sig. pattern \\
\hline 15 & $\begin{array}{l}\text { Analytic hierarchy } \\
\text { process }\end{array}$ & Compound $†$ & $0.519^{*}$ & 9.726 & 1 & 9 & 0.012 & 16.093 & 0.935 & & & Decline \\
\hline 16 & Forecasting analysis & Cubic & 0.599 & 3.483 & 3 & 7 & 0.079 & 21.364 & -7.584 & 1.682 & -0.098 & No sig. pattern \\
\hline 17 & Statistical analysis & Inverse & $0.414^{*}$ & 6.364 & 1 & 9 & 0.033 & 86.549 & 22.835 & & & Decline \\
\hline 18 & $\begin{array}{l}\text { Assignment method } \\
\text { and Transportation me }\end{array}$ & $\begin{array}{l}\text { Logarithmic } \\
\text { thod }\end{array}$ & $0.580^{*}$ & 12.425 & 1 & 9 & 0.006 & 34.821 & -8.629 & & & Decline \\
\hline
\end{tabular}

${ }^{*}$ Resulting $R^{2}$ statistically significant $(P<0.05)$.

† Model is equally significant with growth, exponential, and logistic models in the exact same direction of the life cycle phase pattern. $\ddagger$ Model is a concave function containing growth, maturity, and decline patterns.

lish during the 2004 and 2005 years. A total of 11 textbooks were identified with copyright dates during these 2 years in searches of online textbook retailers, including www. barnesandnoble.com and www.amazon.com. The textbooks selected included Hillier et al. (2004), Render et al. (2005), Anderson et al. (2004a, b), Albright et al. (2004), Winston and Albright (2004), Taylor and Weiss (2004), Daellenbach and McNickle (2005), Kasana and Kumar (2005), Rao and Mishra (2005), and Pinney et al. (2004). Exploring book reviews in the journal, Interfaces, for the purpose of teaching OR revealed a diversity of methodologies. No one textbook contained all the methodologies or models commonly taught in OR courses. For example, the book review by Anis (2006) of the Kasana and Kumar (2005) introductory textbook covered a wide range of programming methodologies, but did not include other commonly used inventory, queuing or simulation methodologies. More recent OR methodology textbooks, such as Anderson et al. (2007) and Render et al. (2008) continue to contain the same sets of methodologies found in the 11 textbooks used for the initial methodology identification sampling effort.

To compensate for the more limited listing of methodology, the criteria for inclusion in the sample for this study was a provision for a wide range of OR topics, as expected in a survey OR textbook. From this review, based on their frequency of listing, a total of 18 major OR methodology categories were identified (see Table 4). The textbooks' chapters presented some overlap and variety of sub-category topics. Consistent with the chapters, we grouped subcategories topics within the major methodology categories. In some cases, like in linear programming, there were no sub-categories, whereas with network analysis, there were many sub-categories added in the citation counts. Any subcategory keyword citation listings were included as a part of the major OR methodology citation count. The total frequency of keyword citations for the 18 major categories in Table 4 ranged for all four journals from 118 to 1,134 for the 11 years covered in this study.

If life cycle phases exist using the keyword data collected, then models that are statistically significant in fitting the data to a predictive equation or model should exist in all 18 of the major categories of OR methodology. While fitting a statistical model significantly to a set of time-related article frequencies does not guarantee a life cycle phase exists in that data, researchers have successfully used this approach to identify trends. Gupta et al. (2006) used frequency counts and curve smoothing to provide an estimate of trends in methodology research publication behavior of the Production and Operations Management Journal. Schniederjans (1995) successfully used this regression approach to find the GP life cycle. Based on this prior research, we used regression analysis as well. This time the SPSS option 

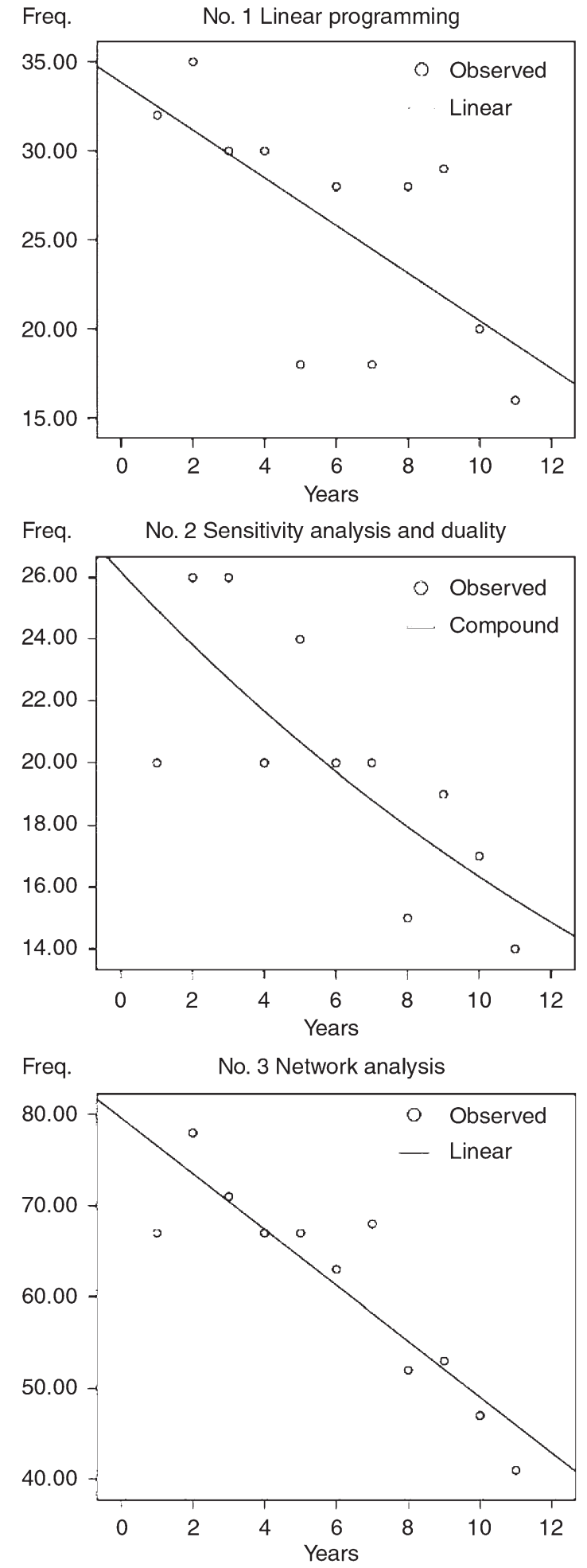

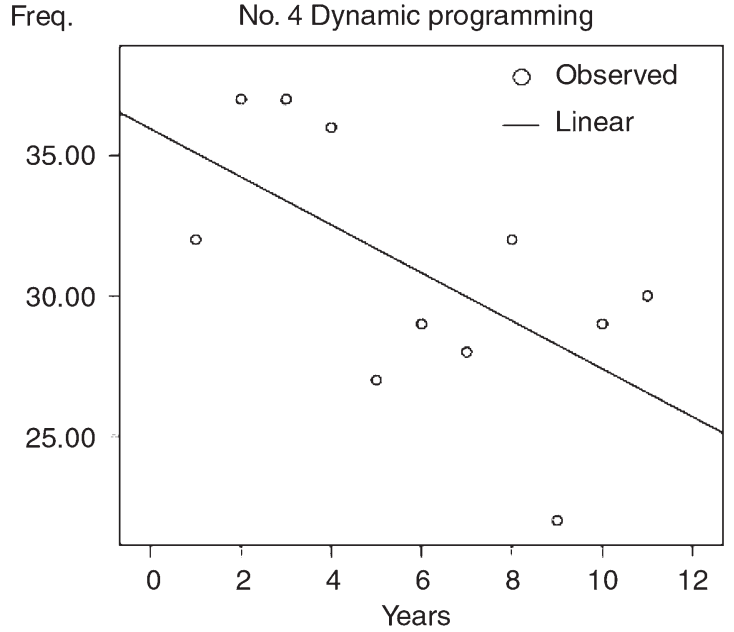

Freq.

No. 5 Game theory

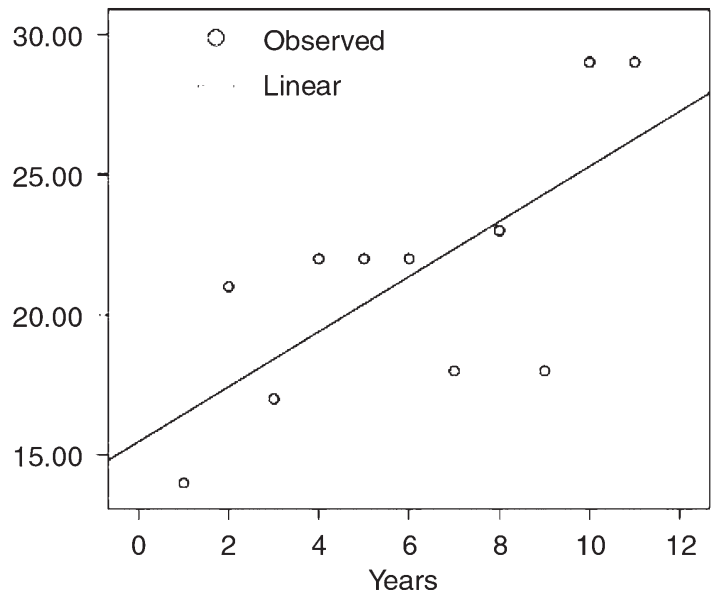

Freq. $\quad$ No. 6 Integer programming

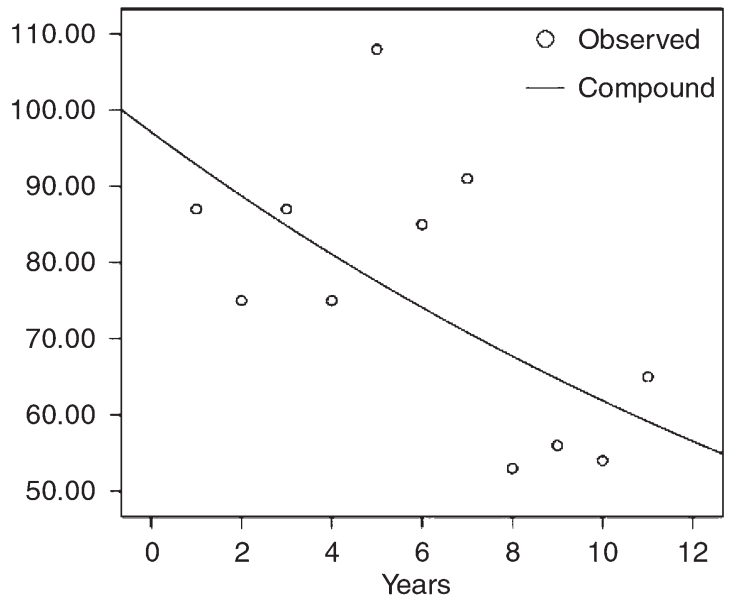

Figure 3. Plot of forecast model and actual values for each of the major methodology categories.

of "curve estimation" is used to find the best data fitting model from the 11 different linear and non-linear models, which the software provides. We are assuming here that the 11 SPSS models (linear, logarithmic, inverse, quadratic, cu- bic, power, compound, S-curve, logistic, growth, and exponential) are adequate for purposes of trend depiction in this study. By allowing the time in years variable to be numbered (i.e., 1, 2, .., 11), as well as the frequencies of journal 

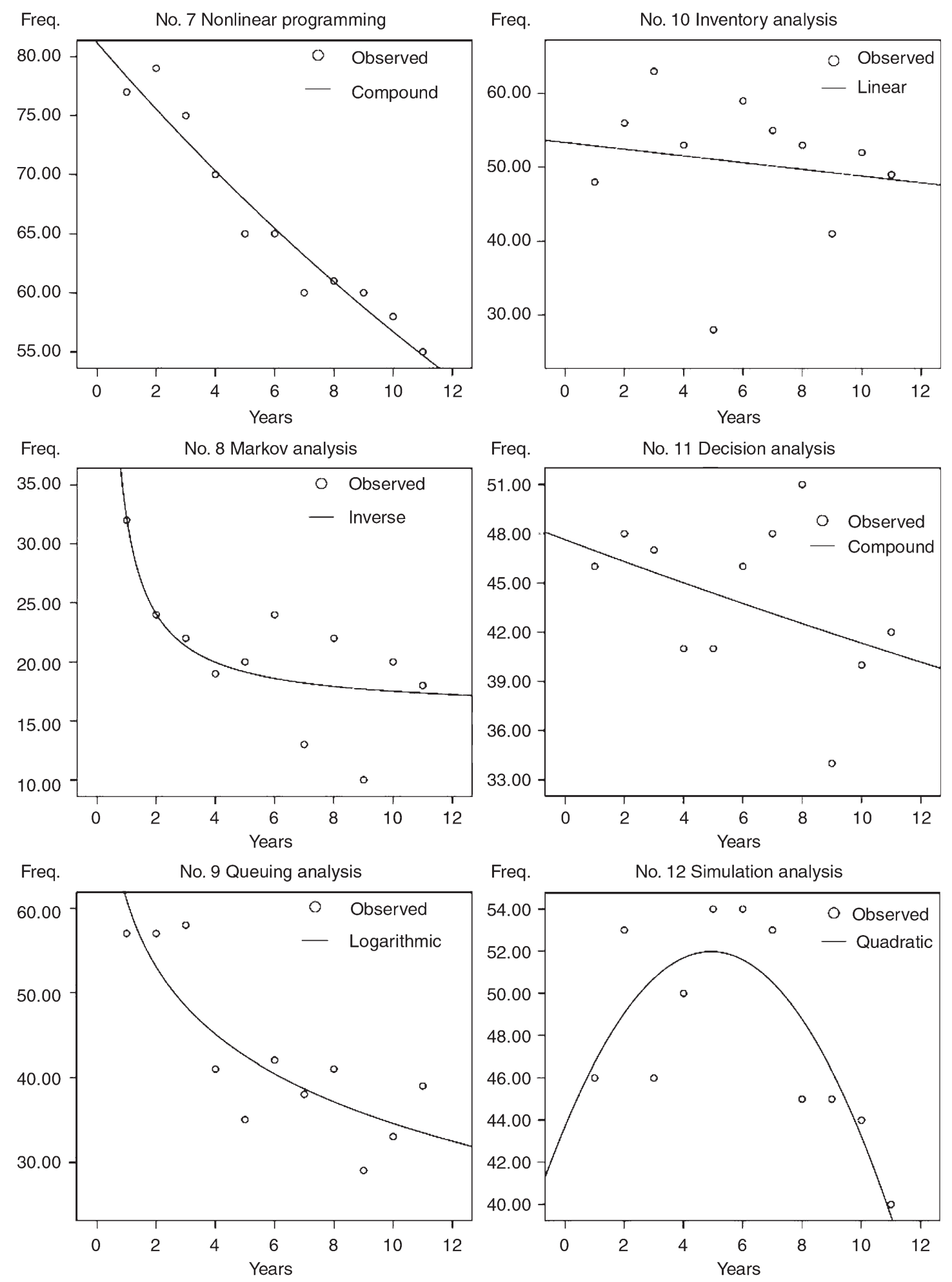

Figure 3 (continued).

article keywords per year used for each of the 18 major OR methodology categories, the best fitting models were selected from the 11 generated for each category. These models and their supporting statistics are presented in Table 5.
All 18 models are plotted in Figure 3. The results of the $r^{2}$ values and $F$-tests presented in Table 5 show that out of the 18 major categories, 14 were significant $(P<0.05)$, and four were not. The life cycle phases for these are easily discern- 

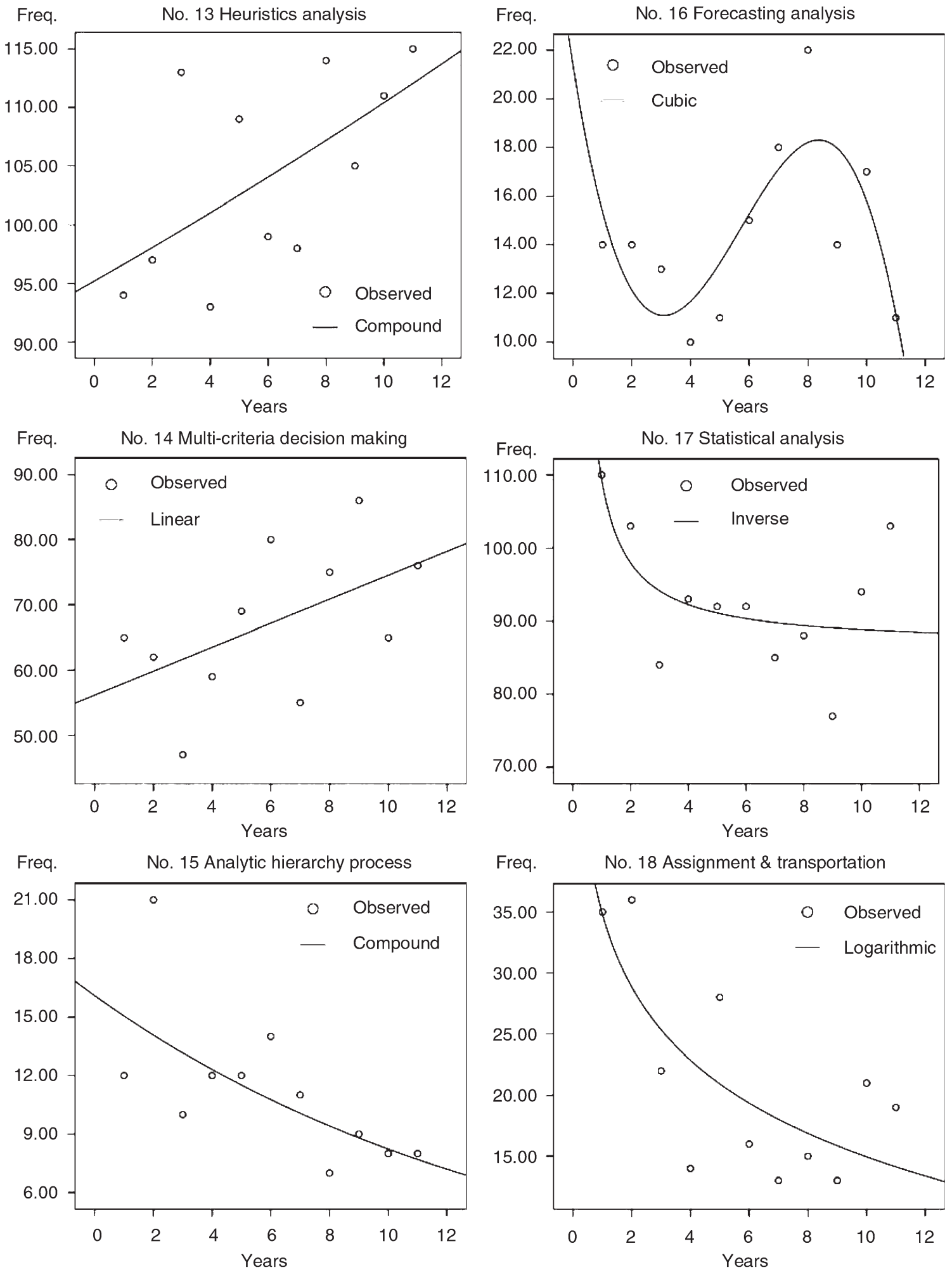

Figure 3 (continued).

ible from the graphic results presented in Figure 3. As one might expect, the best fitting models for these data are both linear and non-linear. While these statistical results do not conclusively confirm that all OR methodologies have life cycle phases, they do depict past methodology usage and suggest possible future phase trend directions. 
Table 6. Listing of additional sub-categories and frequencies

\begin{tabular}{llllr}
\hline No. & $\begin{array}{l}\text { Major methodology } \\
\text { citation categories }\end{array}$ & Content & Sub-categories & $\begin{array}{r}\text { Total frequency of keyword } \\
\text { citation 1994-2004 }\end{array}$ \\
\hline 19 & Not applicable & Algorithms, applications & Data envelopment analysis & 311 \\
20 & Statistical analysis & Algorithms, applications & Combinatorics & 154 \\
21 & Not applicable & Algorithms, applications & Genetic and Neural models & 256 \\
22 & Not applicable & Algorithms, applications & Options analysis & 98 \\
23 & Decision analysis & Algorithms, applications & Utility analysis & 136 \\
24 & Statistical analysis & Algorithms, applications & Risk analysis & 231 \\
25 & Not applicable & Algorithms, applications & Location analysis & 298 \\
26 & Heuristics analysis & Algorithms, applications & Search methods & 294 \\
27 & Not applicable & Algorithms, applications & Fuzzy & 283 \\
28 & Not applicable & Algorithms, applications & Problem structuring methods, Soft OR & 44 \\
\hline
\end{tabular}

Table 7. Resulting predictive model equations, statistics, and life cycle phases for methodology sub-categories

\begin{tabular}{|c|c|c|c|c|c|c|c|c|c|c|c|}
\hline \multicolumn{2}{|r|}{$\frac{\text { No. Sub-category of methodology }}{19 \text { Data envelopment analysis }}$} & $\begin{array}{l}\text { Equation } \\
\text { S-curve }\end{array}$ & $\frac{R^{2}}{0.830^{*}}$ & $\frac{F}{43.904}$ & \multicolumn{2}{|c|}{ df1 df2 } & $\frac{\text { Sig. }}{0.000}$ & $\frac{\text { Constant }}{3.718}$ & $\begin{array}{c}b 1 \\
-1.724\end{array}$ & $b 2$ & $\begin{array}{l}\text { Life cycle phase } \\
\text { Growth }\end{array}$ \\
\hline 20 & Combinatorics & Inverse & $0.561^{*}$ & 11.505 & 1 & 9 & 0.008 & 9.297 & 13.157 & & Decline \\
\hline 22 & Options analysis & Compound & $0.935^{*}$ & 129.677 & 1 & 9 & 0.000 & 3.550 & 1.150 & & Growth \\
\hline 23 & Utility analysis & Compound & 0.140 & 1.469 & 1 & 9 & 0.256 & 14.630 & 0.965 & & No sig. pattern \\
\hline 24 & Risk analysis & Linear & $0.441^{*}$ & 7.087 & 1 & 9 & 0.026 & 17.927 & 0.891 & & Growth \\
\hline 26 & Search methods & Quadratic & $0.802^{*}$ & 16.151 & 2 & 8 & 0.002 & 3.303 & 11.675 & -0.992 & G-M-D pattern $\ddagger$ \\
\hline 27 & Fuzzy methods & Quadratic & $0.740^{*}$ & 11.364 & 2 & 8 & 0.005 & 3.139 & 9.290 & -0.723 & G-M-D pattern $\neq$ \\
\hline 28 & Problem structuring methods & Compound $\dagger$ & $0.835^{*}$ & 20.737 & 1 & 9 & 0.001 & 0.828 & 1.234 & & Growth \\
\hline
\end{tabular}

* Resulting $R^{2}$ statistically significant $(P<0.05)$.

$\dagger$ Model is equally significant with growth, exponential, and logistic models in the exact same direction of the life cycle phase pattern.

$\ddagger$ Model is a concave function containing growth, maturity, and decline patterns.

In the process of collecting the keyword data, a number of additional sub-categories were observed to contain relatively large numbers of keywords. These additional 10 subcategories are listed in Table 6. Note that while several of these OR methodologies might be viewed as stand-alone categories, they are not considered significant enough by the majority of textbook authors to justify an entire chapter to themselves. For this reason, we designate them here as subcategories. For the cases of combinatorics, utility analysis, risk analysis, and search methods, these keyword listings are extracted from their major category keyword totals. Many of these sub-category OR methodologies actually have a greater total frequency of keyword citations in the literature than several of the other major category methodologies.

To examine the existence of life cycle phases in these subcategories, the same regression process used with the major categories was again applied. The resulting models and their supporting statistics are presented in Table 7 and plotted in Figure 4 . The results show that in all but one subcategory (i.e., utility analysis), the fitted models are significant $(P<0.05)$, supporting the existence of life cycle phases in the keyword journal article listings.
In summary, 23 out of 28 models were found to reveal a statistically significant function. This sampling of each methodology's life cycle frequencies appears to reveal life cycle phases that might be useful in predicting future research activity.

\section{Discussion and implications}

While life cycle phases could not be identified for all major category and sub-category OR methodologies defined in this study, most did have a statistically significant fitting model, which clearly depicts a life cycle trend. These results also support the existence of life cycles in most OR methodologies. Several observations and implications warrant reflection and further discussion:

- Life cycle phases revealed: With few exceptions, the significant models fit nicely into linear or non-linear models that appear to accurately depict a life cycle trend. One possible reason for this is that most of the OR methodologies span longer periods of time than the 11-year period used in this study. It stands to reason that a small segment or phase of a total life cy- 

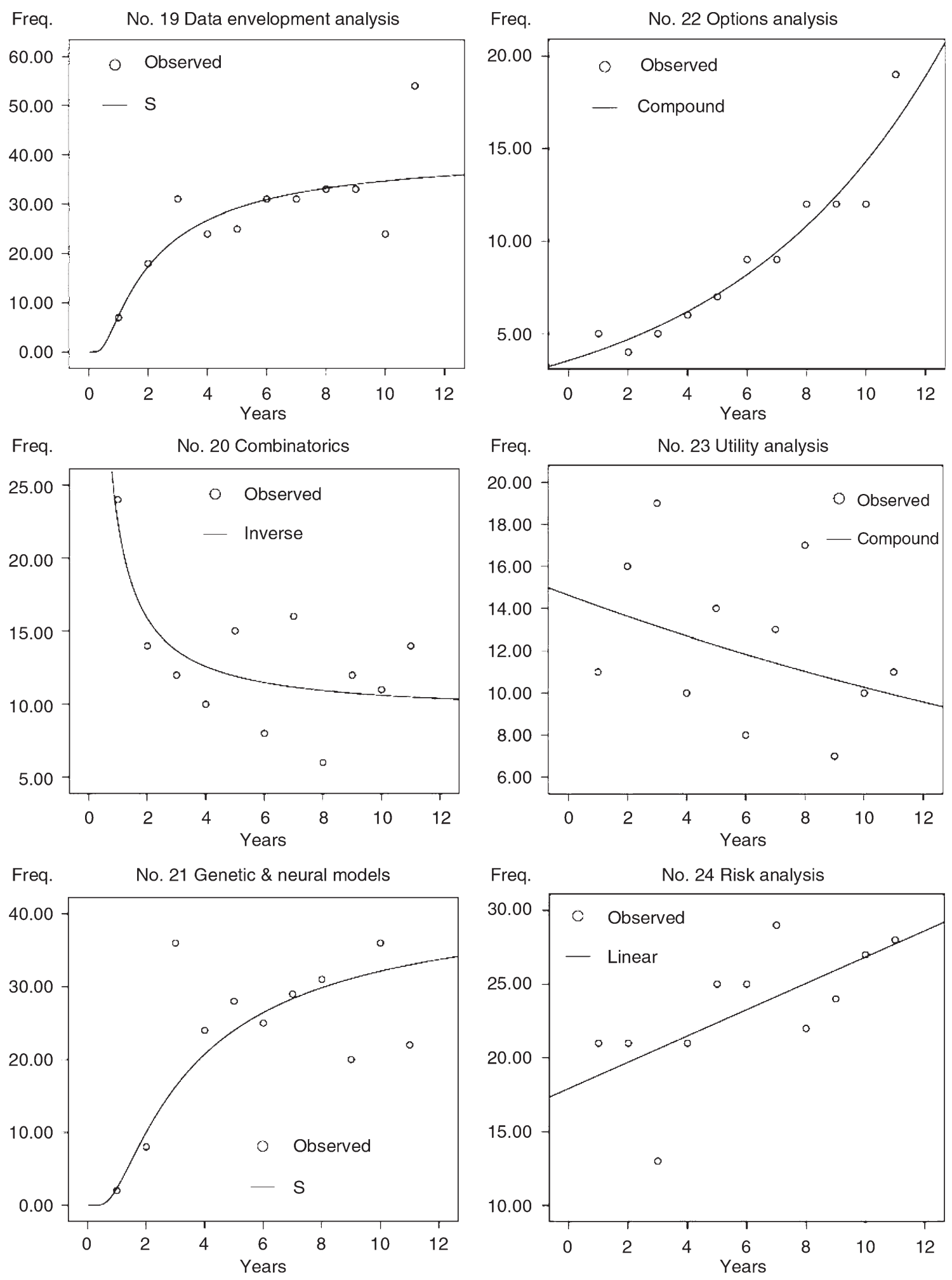

Figure 4. Plot of forecast model and actual values for each of the sub-category methodologies.

cle can be explained by a linear or slightly non-linear function of a much larger non-linear traditional life cycle. This was done in Schniederjans (1995), where only the decline period of 10 years was utilized for prediction purposes, while the entire GP life cycle spanned 35 years. 

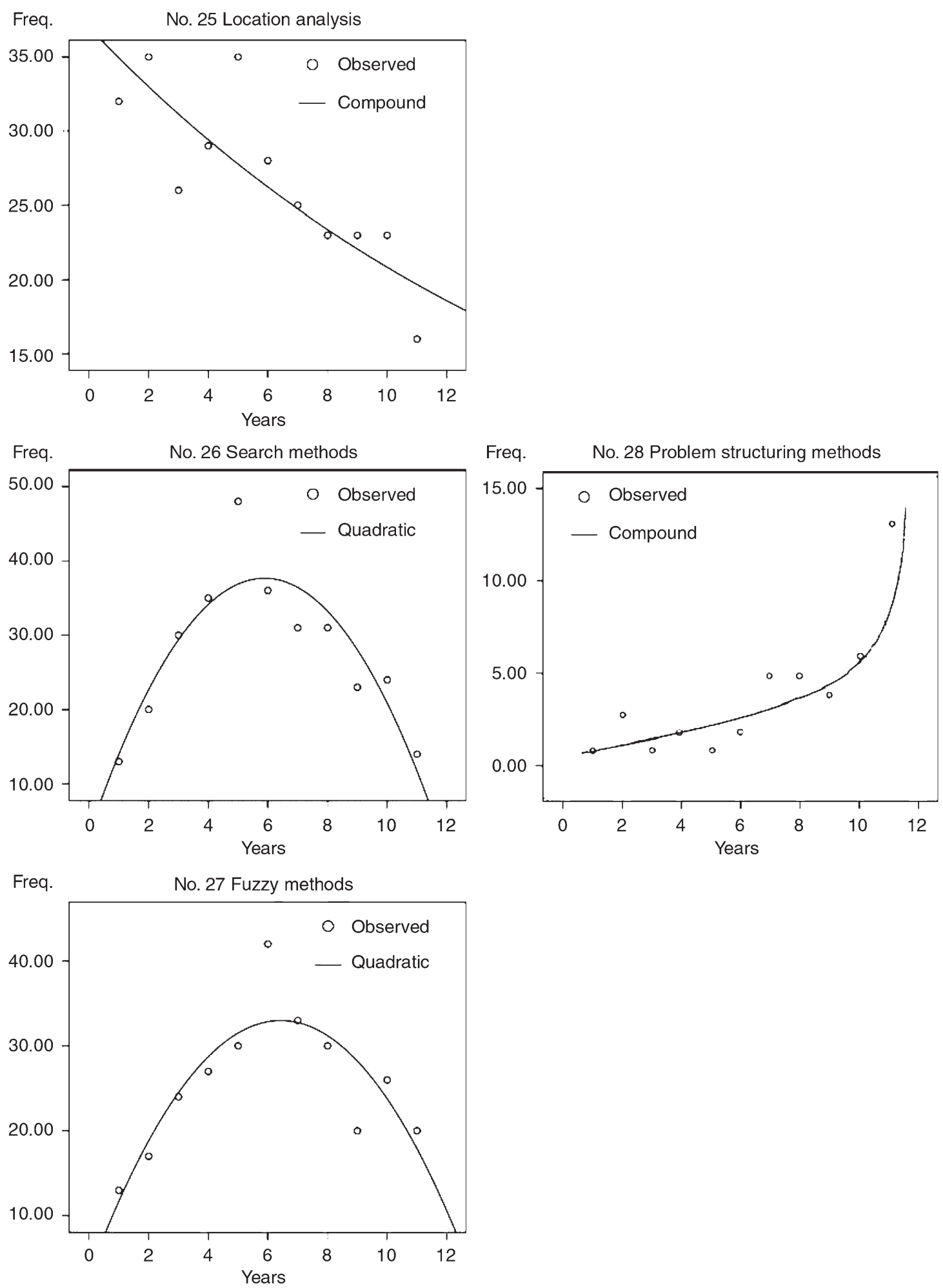

Figure 4 (continued).

- Unique life cycle behavior observed: While most of the life cycle trends reported in this study are single-phased, several of the OR methodologies (i.e., simulation analysis, search methods, and fuzzy methods) depict three phases (i.e., growth, maturity, and decline). Considering the short time interval of years (all of these methods originate in a time period prior to the 1994-2004 periods), this may appear outside the norm of a traditional life cycle. 
Fortunately, there are other life cycle patterns that do fit this variation. As Smaros (2006) has observed a recurring cycling of growth, maturity, and decline phases of a life cycle can repeatedly occur in relatively short periods of time for a product introduced many years previously. For these three methodologies, this may be the case. Also, the growth phases for game theory, heuristic analysis, and risk analysis OR methodologies, which have existed for several decades, may identify the characteristic beginning phase of repeating life cycles.

- A basis for guiding OR textbook content: The journals used for this study are leading-edge journals that provide the latest in OR methodology and application. For the majority of the life cycles of the 14 major significant OR methodology categories, we found 11 were in a decline phase, despite the fact that the total number of journal articles published each year remained fairly constant during the 1994-2004 period. Since the major categories were derived from the chapter headings in recent OR textbooks, this poses the question of whether topics in OR textbooks should be focused on methodologies in other phases (e.g., growth phase) of their life cycles. Perhaps it is appropriate that mature phase or decline phase OR methodologies should be used in OR textbooks to train students in the basic content of OR. On the other hand, it may be argued the growth phase OR methodologies should be given chapter-level attention in future textbooks. It appears from the results presented in Table 7 that the sub-category OR methodologies, like data envelopment analysis, genetic and neural models, options analysis, risk analysis, and problem structuring methods are in a growth phase.

- A basis for guiding OR research: Knowing the position of a methodology in its life cycle can provide useful information for planning future research. For example, scholars, knowing a particular methodology is in a growth phase, might find it a useful indicator of popularity with regard to publication opportunities. Also, another possible contribution could be in guiding funding organizations concerning allocations for further OR research. Unlike product life cycles, where product funding in the decline phase is often cut and products are allowed to disappear from the market (Evans and Berman, 1985, pp 273-274), OR methodologies rarely disappear or become useless. They instead go through periods of more or less frequency of appearance, depending on algorithm or technology advances. This is characteristic of a revival life cycle (Evans and Berman, 1985, p 271). Funding organizations in Europe and U.S., like the National Science Foundation, might better observe and define methodology advancement needs to fund research. The funding for developing extensions or revisions of older maturity or decline phase OR methodologies may help to revive their use and shift their life cycles to a growth phase. Recognizing opportunities to reinvigorate OR methodologies by exploiting life cycle trends is one of the original uses and purposes of life cycle research (Levitt, 1965). As Gordon et al. (1991), Michell et al. (1991), and Chang et al. (2006) point out, funding at opportune times in maturity or decline phases along a life cycle can result in a success strategy for shifting any life cycle to a growth phase. Zanakis and Gupta (1985) have observed new computer software developments and new theoretical developments contribute to expanding the number of publications of OR methodologies, like GP. Funding these developments might also trigger a shifting of the life cycle to a growth phase.

\section{Concluding remarks}

The results of this paper have supported the proposition that article contributions to GP methodology literature could be accurately forecast using a regression model based only on a limited sample of a life cycle trend. Utilizing a similar approach for other OR methodologies, this paper has revealed most of the major categories of commonly used OR methodologies and sub-categories have what appears to be life cycle phases that can be statistically revealed by sampling keywords found in journal articles.

Revealing the possible existence of life cycles for many OR methodologies should not be considered a surprising fact to most OR researchers or practitioners. Intuitively, some topics (or methodologies) are considered currently popular and some not. Knowing which OR methodologies are currently in a growth phase of their life cycles may motivate researchers to use a particular methodology. Yet, any phase of an identified life cycle provides unique opportunities for researchers. For example, linear programming's trend for decades was in either a maturity or decline phase. However, the introduction of the Karmarkar linear programming methodology (Hooker, 1986) helped to push the life cycle of linear programming away from a decline phase when the methodology first appeared. According to Orden (1993), linear programming had a short-lived revival or growth life cycle during the 1980s due in part to the Karmarkar methodology.

Collecting keyword citations from only four journals may be a limitation on the results of this study. Since the four journals selected are all considered leading or cuttingedge journals in their respective geographic regions, we believe they provide a consistency of leadership in the OR field, and therefore, represent a fairly homogenous sampling of high quality OR research articles. While the European Journal of Operational Research represents more than half of all the keywords listed, an examination of the listing of OR methodologies shows a consistency in the percentage of types and frequencies of articles published between the US and European journals. There are only two exceptions: only European journals published fuzzy analysis and problem structuring method articles during the 1994 to 2004 period. We do not feel these inconsistencies causes any invalidation of our findings.

Another dimension of possible sampling bias from the four journals selected concerns the need for a more heterogeneous collection of research reflecting an OR practitioner base. While the selection of top-tier journals might appear to exclude practitioner applications, and with them a more 
Table 8. Resulting predictive linear model equations, statistics, and linear trends for all methodology categories

\begin{tabular}{|c|c|c|c|c|c|c|c|c|c|}
\hline \multicolumn{2}{|r|}{ No. Methodology citation categories } & \multirow{2}{*}{$\begin{array}{l}\text { Eq. } \\
\text { Linear }\end{array}$} & \multirow{2}{*}{$\frac{R^{2}}{0.457^{\mathrm{a}}}$} & \multirow{2}{*}{$\frac{F^{*}}{7.582}$} & \multirow{2}{*}{$\begin{array}{l}\text { Sig. } \\
0.022\end{array}$} & \multirow{2}{*}{$\frac{\text { Constant }}{33.836}$} & \multirow{2}{*}{$\frac{b 1}{-1.336}$} & \multirow{2}{*}{$\frac{\text { Linear trends }^{\mathrm{b}}}{\text { Decline }}$} & \multirow{2}{*}{$\frac{\text { Life cycle trends }{ }^{\mathrm{c}}}{\text { Decline }}$} \\
\hline 1 & Linear programming & & & & & & & & \\
\hline 2 & Sensitivity analysis and duality & Linear & $0.584^{\mathrm{a}}$ & 12.613 & 0.006 & 25.600 & -0.918 & Decline & Decline \\
\hline 4 & Dynamic programming & Linear & $0.376^{\mathrm{a}}$ & 5.423 & 0.045 & 35.945 & -0.855 & Decline & Decline \\
\hline 5 & Game theory & Linear & $0.490^{\mathrm{a}}$ & 8.636 & 0.017 & 15.473 & 0.982 & Growth & Growth \\
\hline 6 & Integer programming & Linear & 0.354 & 4.937 & 0.053 & 94.982 & -3.164 & Decline & Decline \\
\hline 9 & Queuing analysis & Linear & $0.646^{\mathrm{a}}$ & 16.411 & 0.003 & 57.455 & -2.455 & Decline & Decline \\
\hline 10 & Inventory analysis & Linear & 0.025 & 0.234 & 0.640 & 53.364 & -0.455 & Decline & No sig. pattern \\
\hline 11 & Decision analysis & Linear & 0.158 & 1.686 & 0.226 & 47.491 & -0.582 & Decline & No sig. pattern \\
\hline 12 & Simulation analysis & Linear & 0.251 & 3.019 & 0.116 & 52.545 & -0.727 & Decline & G-M-D pattern \\
\hline 13 & Heuristics analysis & Linear & $0.363^{\mathrm{a}}$ & 5.132 & 0.050 & 95.200 & 1.527 & Growth & Growth \\
\hline 14 & Multi-criteria decision making & Linear & 0.281 & 3.519 & 0.093 & 56.164 & 1.836 & Growth & No sig. pattern \\
\hline 19 & Data envelopment analysis & Linear & $0.569^{\mathrm{a}}$ & 11.886 & 0.007 & 12.509 & 2.627 & Growth & Growth \\
\hline 20 & Combinatorics & Linear & 0.192 & 2.145 & 0.117 & 16.673 & -0.627 & Decline & Decline \\
\hline 21 & Genetic and Neural models & Linear & 0.256 & 3.095 & 0.112 & 13.964 & 1.627 & Growth & Growth \\
\hline 22 & Options analysis & Linear & $0.867^{\mathrm{a}}$ & 58.430 & 0.000 & 1.618 & 1.245 & Growth & Growth \\
\hline 23 & Utility analysis & Linear & 0.139 & 1.452 & 0.259 & 14.937 & -0.427 & Decline & No sig. pattern \\
\hline 24 & Risk analysis & Linear & $0.441^{\mathrm{a}}$ & 7.087 & 0.026 & 17.927 & 0.891 & Growth & Growth \\
\hline 25 & Location analysis & Linear & $0.693^{\mathrm{a}}$ & 20.317 & 0.001 & 35.491 & -1.445 & Decline & Decline \\
\hline 26 & Search methods & Linear & 0.005 & 0.048 & 0.831 & 29.091 & -0.227 & Decline & G-M-D pattern \\
\hline 27 & Fuzzy methods & Linear & 0.063 & 0.610 & 0.455 & 21.927 & 0.618 & Growth & G-M-D pattern \\
\hline 28 & Problem structuring methods & Linear & 0.627 & 15.151 & 0.003 & -0.963 & 0.827 & Growth & Growth \\
\hline
\end{tabular}

a Resulting $R^{2}$ statistically significant $(P<0.05)$.

* All F-tests with df1 = 1, df2 $=9$.

$\mathrm{b}$ Based on slope of linear function.

c From original life cycle trends in Tables 5 and 7.

diverse representation of OR research, this appears not to be the case in this study. All four journals selected in this study invite practitioner research as well as theoretical and methodological contributions. To estimate this possible bias, the author associations for 2004 year publications in all four journals were examined, and roughly 20 percent of the articles had one or more authors from industry or government (i.e., non-academic). In addition, we undertook an analysis of a practitioner-oriented journal, Interfaces, to see if the inclusion of keywords for the 28 methodologies might substantially alter the primary findings of this study. By collecting the keywords from Interfaces articles, adding their frequencies to the original frequency distributions, and re-computing new trend models, we observed no changes in the linear trends or life cycle trends originally suggested. While this does not completely discount this type of bias, it lends support to the assertion that practitioners and their more applied research are represented in the sample used in this study.

Another possible limitation of the sampling is that only eleven years of frequencies were used in determining life cycle phases. We recognize that some of the OR methodologies' actual life cycle frequencies might span many de- cades (e.g., Decision Theory). The graphic plots in this paper do not capture an entire life cycle; they only sample a phase or segment of the life cycle function. Moreover, the estimates are offered only as suggestions as to what might be life cycle phases. We recognize that the 11-year period could give false readings of true life cycle phases, because the data used involved only a short interval of time relative to actual total life cycle time periods. In defense, Gupta et al. (2006), using a moving average method, demonstrated life cycle trends in themes, subjects, and methodologies in articles from a single journal using only 11 yearly points of data to plot trends. Also, the original Schniederjans (1995) study only used 10 yearly points out of a 35-year history, which this paper has shown accurately captures the decline phase of GP articles. Finally, as a further check on the results of this paper, we performed comparative analyses between the various suggested linear and non-linear model trends. The linear regression models for all 28 methodologies are presented in Table 8 . Note that in every case where the life cycle trend model predicted growth or decline trend phases, so too did the linear models (see bold text). This concurrence of results helps to support the consistency of the life cycle trend phases reported in this paper. 
A final limitation that may exist in this study is the exclusion of additional sub-categories of new or less frequently used methodologies. Those methodologies selected for inclusion in this study needed to have a sufficient frequency of keyword usage to allow the statistical models to be applied in each of the 11 time periods used in the modeling effort. We leave this limitation as an opportunity further research.

Interested life cycle researchers are encouraged to explore this subject. Adding additional keyword counts by including more journals to improve life cycle accuracy is one possibility for future research. Another extension of this study might be to explore complete individual methodology life cycles for each of the OR methodologies presented in this paper. Each methodological life cycle has its own unique story to tell about itself and its relationship to the field of OR. To assist in that future research, a file in Microsoft Excel format containing a listing of the journal research publications used in this study may be requested of the authors.

\section{References}

Albright S, Winston WL, Winston W, Lapin L, and Whisler W (2004). Spreadsheet Modeling and Applications: Essentials of Practical Management Science. South-Western: Australia.

Allison P and Steward J (1974). Productivity differences among scientists: Evidence for accumulative advantage. Am Sociol Rev 39: 596-606.

Allison P, Long J, and Krauze T (1982). Cumulative advantage and inequality in science. Am Sociol Rev 47: 615-625.

Anderson D, Sweeney D, and Williams T (2004a). An Introduction to Management Science: Quantitative Approaches to Decision Making, 11th edn. South-Western: Australia.

Anderson D, Sweeney D, and Williams T (2004b). Quantitative Methods for Business with EasyQuant Tutor for Excel, 9th edn. South-Western: Australia.

Anderson D, Sweeney D, Williams T, and Kipp R (2007). An Introduction to Management Science: Quantitative Approaches to Decision Making, 12th edn. South-Western: Australia.

Anis M (2006). Book review. Introductory operations research: Theory and applications. Interfaces 36: 273-274.

Bayer A and Dutton J (1977). Career age and research-professional activities of academic scientists. J Higher Educ 48: 59-282.

Chang S-L, Wang R-C, and Wang S-Y (2006). Applying fuzzy linguistic quantifier to select supply chain partners at different phases of product life cycle. Int J Prod Econ 100: 348-359.

Charnes A and Cooper W (1961). Management Models and Industrial Applications of Linear Programming. John Wiley and Sons: New York. Vols. 1 and 2.

Cole S (1979). Age and scientific performance. Am J Sociol 84: 958-977.

Daellenbach H and McNickle D (2005). Management Science: Decision-Making Through Systems Thinking. Palgrave Macmillan: New York.

Diamond A (1984). An economic model of the life-cycle research productivity of scientists. Scientometrics 6: 189-196.

Diamond A (1986). The life-cycle research productivity of mathematicians and scientists. J Gerontol 41: 520-525.
Du R and Kamakura W (2006). Household life cycles and lifestyles in the United States. Journal of Marketing Research 43: 121-132.

Evans J and Berman B (1985). Marketing, 2nd edn. Macmillan Publishing: New York.

Gordon G, Calantone R, and di Benedetto C (1991). Mature markets and revitalization strategies: An American fable. Bus Horizons 34: 39-50.

Grieves M (2005). Product Lifecycle Management. McGraw-Hill: Boston, MA.

Gupta S, Verma R and Victorino L (2006). Empirical research publishing in Production and Operations Management (19922005): Trends and future research directions. Prod Opns Mngt 15: 432-448.

Hellman T (1994). Thinking in cycles. Across Board 31: 55.

Hillier F, Lieberman GJ, and Liberman G (2004). Introduction to Operations Research, 8th edn. McGraw-Hill: Boston, MA.

Hooker J (1986). Karmakar's linear programming algorithm. Interfaces 16(4): 75-90.

Kasana H and Kumar K (2005). Introductory Operations Research: Theory and Applications. Springer: New York.

Lehman H (1953). Age and Achievement. Princeton University Press: Princeton, NJ.

Levin S and Stephan P (1991). Research productivity over the life cycle: Evidence for academic scientists. Am Econ Rev 81: 114-132.

Levitt T (1965). Exploit the product life cycle. Harvard Bus Rev 43: 81-94.

Michell P, Quinn P, and Percival E (1991). Marketing strategies for mature industrial products. Ind Market Mngt 20: 201-206.

Orden A (1993). LP from the '40s to the '90s. Interfaces 20(5): 158-165.

Pinney W, McWilliams D, Ormsby J and Atchison M (2004). Quantitative Methods for Management, 3rd edn. Thomson Learning: Australia.

Rao K and Mishra S (2005). Operations Research. Alpha Science International: New York.

Render B, Stair R, Hanna M, Hanna M, and Stair Jr. R (2005). Quantitative Analysis for Management, 9th edn. Pearson Education: Upper Saddle River, NJ.

Render B, Stair R, and Hanna M (2008). Quantitative Analysis for Management, 10th edn. Pearson Education: Upper Saddle River, NJ.

Saaksyuori A and Immonen A (2005). Product Lifecycle Management. Springer-Verlag: New York.

Schniederjans M (1995). The life cycle of goal programming research as recorded in journal articles. Opns Res 43: 551-557.

Smaros J (2006). Collaborative forecasting: A selection of practical approaches. Int J Logist Res Appl 6: 245-258.

Spurr W and Bonini C (1973). Statistical Analysis for Business Decisions, revised edn. Richard D. Irwin: Homewood, IL.

Taylor B and Weiss H (2004). Introduction to Management Science and Student CD-ROM with POM/QM for Windows Version 2.2 CDROM Package, 8th edn. Pearson Education: Upper Saddle River, NJ.

Winston W and Albright S (2004). Practical Management Science: Spreadsheet Modeling and Applications, 2nd edn. South-Western: Australia.

Zanakis S and Gupta K (1985). A categorized bibliographic survey of goal programming. Omega 13: 211-222. 